\title{
The golden years of Norwegian epidemiology
}

\author{
Dag S. Thelle \\ Department of Biostatistics, Institute of Basic Medical Sciences, University of Oslo \\ Department of Public Health and Community Medicine, Sahlgrenska Academy, University of Gothenburg \\ E-mail: epidag@gmail.com
}

\begin{abstract}
This is an open access article distributed under the Creative Commons Attribution Licence, which permits unrestricted use, distribution, and reproduction in any medium, provided the original work is properly cited.
\end{abstract}

GOLDEN YEARS has at least two different meanings in English. It may for instance imply both the peak years of an activity, and the years after retirement when one is appreciating a slightly more quiet life. I guess that the Norwegian editors were thinking about the Golden Years as the most productive and innovative years within the realm of epidemiology in Norway when they asked me to comment on Norwegian epidemiology. Within the latter, the Golden Years would be the present time, as today is when we have the largest number of researchers, and probably also the highest level of epidemiological competence ever in this country. It is trivial to state that this is the result of what has been done in the past, but it feels appropriate to highlight some that lead toward the current promising situation. The two main speakers (among many contributors) at the founding meeting of the Norwegian Epidemiology Association in Bergen in 1990 were Professor Geoffrey Rose from London School of Hygiene and Tropical Medicine, and Professor Olli Miettinen from EMGO Institute, Free University in Amsterdam. Miettinen ended his talk on Visions of the Future by envisioning the future epidemiologist as someone concerned with his or her favourite disease, and attending meetings concerning that disorder rather than "pure" epidemiological conferences. The future epidemiologist will only secondarily be associated with community preventive programs, and etiological research will turn to the clinical challenge rather than prevention. Public health scientists will, according to Miettinen "gain clarity and refinement in their selfdefinition and sense of mission, and secondarily in their relation to epidemiological research". In contrast, Geoffrey Rose emphasized the role of epidemiology as a bridge between clinicians and public health. The increasing burden of chronic diseases where treatment options remain limited and that are rarely curable, led to the demand for effective prevention. He also underlined the need for risk assessments and the use of attributable risk estimates when prioritizing preventive efforts. Both speakers pointed at need for credible and valid evidence before taking actions.

We can approach epidemiology from two main perspectives. One is from the health issues at stake: which problems are facing us at the present and how to solve them. The second is to concentrate on research avenues that are available to us, and to further refine these analytical instruments. It is fair to say that Norwegian epidemiological research has aimed more at the first perspective than the second, even if advanced methodologists have emerged during the last three decades $(1,2)$. In this brief overview I will concentrate on some major fields: cardiovascular disease, cancer and peri- and neonatal, and social class epidemiology. This is highly selective and unfair to other fields, for instance osteoporosis, but the present book will hopefully balance my lack of fairness.

\section{Cardiovascular diseases}

A year to start could be 1964 when Jervell et al. showed that mortality rates of coronary heart disease (CHD) varied considerably across Norway. The differences could to a large extent be explained by variation in total serum cholesterol level (3). Later Westlund and Nicolaysen confirmed that total cholesterol acted as a major risk factor for coronary heart disease in middleaged men in Norway (4). The rationale for these studies was the remarkable decline in CHD mortality during World War II in Norway followed by the rapid increase in cardiovascular mortality during the following decades after the war (5). This was not the beginning of Norwegian epidemiological research but it laid the foundations for a number of further studies aiming at understanding the reasons for cardiovascular trends and regional differences. The age- and cause-specific mortality at county levels for the period 1959-1962 was analysed for the first time in 1965, and showed quite unexpectedly that the northern and more rural areas in Norway had the highest coronary heart disease mortality rates, even higher than Oslo. A subsequent mortality analysis for the period 1964-1967 showed that the increase in CHD mortality rates were clearly higher in the three northernmost counties than the national average. When the 1964-1967 data became available it was decided by the newly-established University of Tromsø that a population study aiming at identifying the major cardiovascular risk factors should be undertaken (6). The first chair of epidemiology at a Norwegian university was offered to Knut Westlund who was to become highly influential in the further development of epidemiology in Northern Norway.

The Tromsø Heart Study and the Cardiovascular Disease Studies in Norwegian Counties both started in 1974 followed the cross-sectional layout of the Oslo Diet and Stop Smoking Study $(7,8)$. The National Health Screening Service in cooperation with the universities carried out the Cardiovascular Disease Studies 
in Norwegian Counties. A major asset of these studies was that the respective planning committees had some members in common so that future comparability could be secured as a major objective. This resulted in almost identical main questionnaires, and to some extent centralized laboratory services, or at least parallel analyses to insure comparability. The data collection followed a standardized procedure both regarding survey instruments and laboratory assessments. During the years 1994-2003, a number of health surveys that were carried out in other counties and cities also provided similar data for the network. These studies constitute the COhort of NORway, or CONOR. The purpose of CONOR is to investigate causes of disease on a broad basis. The total number of participants is around 200,000 (9). CONOR contains health data including lifestyle, social variables, laboratory data and stored blood samples, and is based on collaboration between the Norwegian Institute of Public Health and the universities of Oslo, Bergen, Trondheim and Tromsø.

An example of the use of CONOR data was the analysis of the potential protective role of alcohol on coronary heart disease. This resulted in a report in 2011 which showed that moderate consumption of alcohol was associated with decreased risk of coronary deaths, but that this association was not related to high-density lipoprotein cholesterol (10). The sheer size of the study cohort and the standardization of the exposure variable ascertainment make the study an invaluable source for future research topics. The administrative responsibility for CONOR was given to the Norwegian Institute of Public Health (NIPH) in 2002.

\section{CANCER EPIDEMiology}

The major prerequisite for cancer epidemiology in Norway was the establishment of a Norwegian Cancer Registry in 1951. This registry is nationwide and one of the oldest national cancer registries in the world. It is compulsory by law for all medical doctors in the country to report new cancer cases to the registry. The register must be notified in case of cancer suspicion, even without a verified cancer diagnosis, and also if cancer is first diagnosed by autopsy. In case of doubt, a notification must be sent. This implies a high grade of completeness, and the registry is unique as a endpoint register for epidemiological studies, such as CONOR. The longitudinal study initiated by Erik Bjelke in 1966 is probably the best example of an early epidemiological study from Norway aiming at etiological factors for cancer (11). The study was based upon postal questionnaires covering different aspects of lifestyle including diet. It was one of the largest longitudinal studies established in Norway during the 1960 s, and the cohort was followed for twenty years. Among the findings were the protective effects of vitamin A for lung cancer in smokers, and the inverse association between coffee and colon cancer (12-14).
About 15 years after the Tromsø Heart Study was initiated, a cohort study investigating female cancer was established with its main base in Tromsø (15). This national study is called The Norwegian Women and Cancer study (NOWAC). NOWAC is a large population-based cohort study, the aim of which is to prospectively examine the associations between different lifestyle factors and the risk of various diseases in a representative sample of the general Norwegian female population. The research centre is in Tromsø, but the study has strong international links with among others, the European Prospective Investigation into Cancer and Nutrition (http://epic.iarc.fr/). EPIC is one of the largest cohort studies in the world focusing at cancer, and NOWAC contributes considerably to this databank.

Between 1991 and 2010, a total of 172,000 women aged 30-70 years were enrolled in the NOWAC Study. The participants completed a self-administered questionnaire on lifestyle, health, and diet. Linkage with the Cancer Registry of Norway was performed to determine cancer incidence until December 31, 2009. The study enabled researchers to analyse the importance of validated exposure data of diet, and lifestyle in a well-defined population. The study entails repeated collection of exposure information every 5-7 years with complete coverage using the national address register.

The endpoint registration comprises validated follow-up of cancer, mammograms, causes of death, and emigrations, based on national register linkages using the personal identification number.

The study design enables researchers to assess the incidence of different cancer forms as well as other chronic diseases. The national character of the study ensures generalizability and external validity for the Norwegian female population. Attributable fractions for the different exposure variables can be calculated from the exposure data and the disease frequencies. Among the published findings was that NOWAC did not support an association between intestinal cancer and intake of red meat, chicken, or meat cooking methods, but a high intake of processed meat (e.g. sausages) was associated with increased risk of proximal colon, distal colon and rectal cancer (16). The study provides unique possibilities to assess the effect of screening for breast cancer, and to explore the efficacy of different survey assays $(17,18)$. A primary emphasis is placed on lifestyle factors such as diet and leisure time physical activity $(19,20)$.

\section{PERI- AND NEONATAL EPIDEMIOLOGY}

The thalidomide tragedy was one of the reasons for establishing The Medical Birth Registry of Norway in 1967 (21). Thalidomide had been marketed in 1957 in West Germany and, shortly after the drug was introduced, between 5,000 and 7,000 infants were born with malformed limbs. Throughout the world, about 10,000 cases were reported due to thalidomide. Further 
arguments for a birth registry were increasing concern with environmental pollutants. The Chernobyl accident in 1986 was an eye-opener, underlining the need for linkage between the registry and exposure variables (22). An important management function of the registry is the epidemiological surveillance of perinatal health problems (23). This has contributed to the identification of a series of clusters and thereby to reducing the uncertainty attached to birth defects and the environment. The combination of reliable (i) personal identification numbers, (ii) geographical coordinates of the population, (iii) large cohorts of populations screened over time for background information and health variables, (iv) well-organized biobanks, (v) a national network for analyses in genetics/molecular biology, and (vi) a series of very good registers of health outcomes provides an internationally unique combination.

\section{SOCIAL CLASS AND EDUCATION}

In a review in Nature in 1989, David Barker discussed change in the major diseases of the industrialized world during the $20^{\text {th }}$ century (24). He was one of the first researchers to take up the hypothesis formulated by Anders Forsdahl, that maternal living conditions during pregnancy and the first years of childhood have an important impact on the risk of chronic disorders later in life, especially cardiovascular diseases (25). The importance of this work, which is now part of a theory called fetal programming, was also popularized in Newsweek in autumn 1999, and is considered as an important contribution to our thinking on the etiology of chronic diseases. See also (http://www.thebarker theory.org/science.php). As a community physician Anders Forsdahl had first-hand experience, of poverty coupled with high incidence of cardiovascular disease. This formed the basis for his hypothesis.

The impact of socio-economic inequality as cause of disease was otherwise not a major research focus from the 1950s to 1970 s, neither in Norway or internationally. A search internationally for scientific papers with keywords such as poverty, epidemiology and social class results in 12 references for the 10-year period 1966-1975. Twenty years later 160 papers could be identified on the same issues. The general opinion from the 1950 s to the 1970 s seemed to be that welfare states led by social democrats had evened out class differences with regard to health status as well as other issues. Thus interest in investing in research on the effects of social class on health was modest. A similar reluctance was seen both in the U.S. under President Ronald Reagan, and the UK under Prime Minister Margaret Thatcher. In the U.S. a research program at the National Institutes of Health lead by Elliot Liebow on the association between social inequality and health was closed down, and the Black Report in the UK from 1980 suffered an attempt to restrict its publication (26).

This did not mean that such research was entirely stopped in the UK. From the group of Geoffrey Rose and Michael Marmot came a number of reports, mainly based upon the Whitehall Study, which showed how social status had a profound effect on morbidity and mortality (27). Similar observations emerged from Norway too, but at that time this research did not have the same impact on political life as in the UK (28). Over the next three decades, however, an abundance of reports were published, resulting in, among others, the so-called Marmot report from 2010 (29).

A recent analysis of the association between educational attainment and longevity in Norway showed that life expectancy of the age of 35 year olds increased remarkably between 1961 and 2009 for all education groups (30). But during this period inequalities in life expectancy between tertiary and primary education categories widened by 5.3 years for men and 3.2 years for women. At the same time as the proportion of subjects with tertiary education increased from approximately 12 per cent during the 1960 s to 35 per cent today the probability of women with primary education surviving to age 64 did not improve at all. The gain in life expectancy lagged about 10 years compared to higher education groups, which may mean that improvements in life-sustaining factors reached various segments of the population at different times.

Attained education can be looked upon as a proxy for social status, and the analysis confirms what is already well known about mortality and social class. It may seem contradictory that an egalitarian country such as Norway still demonstrates such differences that must be linked to social status. The epidemiological question is why such differences exist, and for the public health authorities whether it is feasible to reduce their impact.

\section{AN ASSISTED SUCCESS STORY}

The establishment of a chair in epidemiology at the University of Tromsø (The Arctic University) in 1973 was followed twelve years later by setting up a department of epidemiology at the National Institute of Public Health. The Medical Research Council (MRC) had already supported research-training courses in biostatistics and epidemiology during the latter half of the 1970s, courses that were shared between the universities of Bergen, Oslo and Tromsø. The MRC later supported chairs in epidemiology at each of the four medical schools at the universities in Norway. An advisory committee was set up to guide epidemiological research. Fredrik Melbye and professor Leiv S. Bakketeig were pivotal figures in this committee. The current bright status of Norwegian epidemiology is a result of some far-sighted individuals, a lot of hard work, and dedicated fundraisers (and some luck). 


\section{REFERENCES}

1. Aalen OO, Røysland K, Gran JM, Ledergerber B. Causality, mediation and time: a dynamic viewpoint. J R Stat Soc Ser A Stat Soc 2012; 175 (4): 831-61.

2. Svensson E, Moger TA, Tretli S, Aalen OO, Grotmol T. Frailty modelling of colorectal cancer incidence in Norway: indications that individual heterogeneity in risk is related to birth cohort. Eur J Epidemiol 2006; 21 (8): 587-93.

3. Jervell A, Meyer K, Westlund K. Coronary heart disease and serum cholesterol in males in different parts of Norway. Acta Med Scand 1965; 177: 13-23.

4. Westlund K, Nicolaysen R. Serum cholesterol and risk of mortality and morbidity. A 3-year follow-up of 6,886 men. Scand J Clin Lab Invest Suppl 1966; 87: 1-19.

5. Strom A, Jensen RA. Mortality from circulatory diseases in Norway 1940-1945. Lancet 1951; 1 (6647): 126-9.

6. Thelle DS, Førde OH, Try K, Lehmann EH. The Tromsø heart study. Methods and main results of the crosssectional study. Acta Med Scand 1976; 200 (1-2): 107-18.

7. Bjartveit K, Foss OP, Gjervig T, Lund-Larsen PG. The cardiovascular disease study in Norwegian counties. Background and organization. Acta Med Scand Suppl 1979; 634: 1-70.

8. Hjermann I, Velve Byre K, Holme I, Leren P. Effect of diet and smoking intervention on the incidence of coronary heart disease. Report from the Oslo Study Group of a randomised trial in healthy men. Lancet 1981; 2 (8259): 1303-10.

9. Næss O, Søgaard AJ, Arnesen E, Beckstrøm AC, Bjertness E, Engeland A, et al. Cohort profile: cohort of Norway (CONOR). Int J Epidemiol 2008; 37 (3): 481-5.

10. Magnus P, Bakke E, Hoff DA, Høiseth G, Graff-Iversen S, Knudsen GP, et al. Controlling for high-density lipoprotein cholesterol does not affect the magnitude of the relationship between alcohol and coronary heart disease. Circulation 2011; 124 (21): 2296-302.

11. Bjelke E. Dietary vitamin A and human lung cancer. Int J Cancer 1975; 15 (4): 561-5.

12. Vollset SE, Bjelke E. Does consumption of fruit and vegetables protect against stroke? Lancet 1983; 2 (8352): 742 .

13. Heuch I, Kvåle G, Jacobsen BK, Bjelke E. Does pancreatic cancer lead to an increased coffee consumption? Lancet 1985; 1 (8424): 339.

14. Jacobsen BK, Bjelke E, Kvåle G, Heuch I. Coffee drinking, mortality, and cancer incidence: results from a Norwegian prospective study. $J$ Natl Cancer Inst 1986; 76 (5): 823-31.

15. Lund E, Dumeaux V, Braaten T, Hjartåker A, Engeset D, Skeie G, et al. Cohort profile: The Norwegian Women and Cancer Study - NOWAC - Kvinner og kreft. Int J Epidemiol 2008; 37 (1): 36-41.

16. Parr CL, Hjartåker A, Lund E, Veierød MB. Meat intake, cooking methods and risk of proximal colon, distal colon and rectal cancer: the Norwegian Women and Cancer (NOWAC) cohort study. Int J Cancer 2013; 133 (5): 1153-63.

17. Lund E, Mode N, Waaseth M, Thalabard JC. Overdiagnosis of breast cancer in the Norwegian Breast Cancer Screening Program estimated by the Norwegian Women and Cancer cohort study. BMC Cancer 2013; 13: 614.

18. Illner AK, Harttig U, Tognon G, Palli D, Salvini S, Bower E, et al. Feasibility of innovative dietary assessment in epidemiological studies using the approach of combining different assessment instruments. Public Health Nutr 2011; 14 (6): 1055-63.

19. Borch KB, Braaten T, Lund E, Weiderpass E. Physical activity and mortality among Norwegian women - the Norwegian Women and Cancer Study. Clin Epidemiol 2011; 3: 229-35.

20. Gavrilyuk O, Braaten T, Skeie G, Weiderpass E, Dumeaux V, Lund E. High coffee consumption and different brewing methods in relation to postmenopausal endometrial cancer risk in the Norwegian Women and Cancer Study: a population-based prospective study. BMC Women's Health 2014; 14: 48.

21. Bjerkedal T, Irgens LM [Medical birth registries a gold mine for research]. Nord Med 1993; 108 (8-9): 211-2, 8.

22. Irgens LM, Lie RT, Ulstein M, Skeie Jensen T, Skjærven R, Sivertsen F, et al. Pregnancy outcome in Norway after Chernobyl. Biomed Pharmacother 1991; 45 (6): 233-41.

23. Irgens LM, Skjærven R, Lie RT. Secular trends of sudden infant death syndrome and other causes of post perinatal mortality in Norwegian birth cohorts 1967-1984. Acta Paediatr Scand 1989; 78 (2): 228-32.

24. Barker DJ. Rise and fall of Western diseases. Nature 1989; 338 (6214): 371-2.

25. Forsdahl A. Living conditions in childhood and subsequent development of risk factors for arteriosclerotic heart disease. The cardiovascular survey in Finnmark 1974-75. J Epidemiol Community Health 1978; 32 (1): 34-7.

26. Blane D. An assessment of Black Report's explanations of health inequalities. Sociol Health Illness 1985; 7 (3): 423-45.

27. Rose G, Marmot MG. Social class and coronary heart disease. Br Heart J 1981; 45 (1): 13-9.

28. Holme I, Helgeland A, Hjermann I, Leren P. Socio-economic status as a coronary risk factor: the Oslo study. Acta Med Scand Suppl 1982; 660: 147-51.

29. Marmot M. Fair society, healthy lives. London: University College London, 2010.

30. Steingrímsdóttir OA, Næss $\varnothing$, Moe JO, Grøholt EK, Thelle DS, Strand BH, et al. Trends in life expectancy by education in Norway 1961-2009. Eur J Epidemiol 2012; 27 (3): 163-71. 